\title{
GENERAL INDEX
}

\author{
$1914-1924$
}

\section{AUTHORS}

Adams, E. P. See Reviews, under Institut, Pringsheim, P., Rougier.

Alexander, J. W. Note on Riemann Spaces, XXVI, 370.

Allen, E. F. The Jacobian of a Contact Transformation, XXX, 335.

Allen, E. S. See Reviews, under Jung, Sommerville, Zeuthen.

Allen, F. E. See Reviews, under Wentworth.

Altshiller, N., Altshiller-Court, N. See Court, N. A.

ARchibald, R. C. A Correction, XXII, 100.

- Concerning Reviews, XXII, 399.

- Note on Editions of Von Staudt's Geometrie der Lage, XXV, 132.

- See Reviews, under Braude, Byerly, Carslaw, Exposition, Fehr, Gibson, Goldenring, Hobson, Kerst, Kommerell, V., Lebon, Lobachevski, Lorey, Miller, G. A., Moritz, Picard, Science and Learning, Science and the Nation, Smith, D. E., Teixeira, Thompson, D'A. W.

BarnetT, I. A. Integro-Differential Equations with Constant Limits of Integration, XXVI, 193.

- See Reviews, under Evans, G. C.

Bateman, H. The Structure of the Ether, XXI, 299.

- A Certain System of Linear Partial Differential Equations, XXII, 329.

- The Solution of the Wave Equation by Means of Definite Integrals, XXIV, 296.

- Rotating Cylinders and Rectilinear Vortices, XXV, 358.

- Notes on Electrical Theory, XXVII, 217.

- An Electromagnetic Theory of Light-Darts, XXIX, 385.

- See Reviews, under Robb.

Batta, M. A. See Loria, G.

Beatty, S. The Inversion of an Analytic Function, XXIII, 347.

Beetle, R. D. See Reviews, under Brodetsky.

BeLL, E. T. Report of a Special Meeting of the San Francisco Section, XXVII, 1.

- Some Remarkable Determinants of Integers, XXIV, 376.

- A Partial Isomorph of Trigonometry, XXV, 311.

- On the Number of Representations of $2 n$ as a Sum of $2 r$ Squares, XXVI, 19.

- Definitions and Illustrations of New Arithmetical Group Invariants, XXVI, 211.

- The Equation $d s^{2}=d x^{2}+d y^{2}+d z^{2}, \quad$ XXVI, 312 .

- An Image in Four-Dimensional Lattice Space of the Theory of the Elliptic Theta Functions, XXVII, 153.

- Proof of an Arithmetic Theorem Due to Liouville, XXVII, 273.

- On a General Arithmetic Formula of Liouville, XXVII, 330.

- Extensions of Dirichlet Multiplication and Dedekind Inversion, XXVIII, 111.

- A Revision of the Bernoullian and Eulerian Functions, XXVIII, 443.

- Square-Partition Congruences, XXIX, 349.

- Analogies between the $u_{n}, v_{n}$ of Lucas and Elliptic Functions, XXIX, 401.

- On Certain Quinary Quadratic Forms, XXX, 127. 
BeLL, E. T. The Class Number Relations implicit in the Disquisitiones Arithmeticae, $\mathrm{XXX}, 236$.

- Reductions of Enumerations in Homogeneous Forms, XXX, 345.

- Complete Class Number Expansions for Certain Elliptic Theta Constants of the Third Degree, XXX, 493.

- See Reviews, under Dickson.

Bennett, A. A. An Elementary Derivation of the Probability Function, XXIV, 477.

- Products of Skew-Symmetric Matrices, XXV, 455; XXVI, 280.

- Poncelet Polygons in Higher Space, XXVI, 274.

- Five Axioms for Point and Translation in Affine Geometry, XXX, 520.

Bernstein, B. A. Reports of Meetings of the San Francisco Section, XXIV, 417; XXV, 193, 393; XXVI, 152, 396; XXVII, 149.411; XXVIII, 94, 281; XXIX, 10, 193.

- A Simplification of the Whitehead-Huntington Set of Postulates for Boolean Algebras, XXII, 458.

- The Complete Existential Theory of Hurwitz's Postulates for Abelian Groups and Fields, XXVIII, 397; XXIX, 33.

Complete Sets of Representations of Two-Element Algebras, XXX, 24.

- A Generalization of the Syllogism, XXX, 125.

- See Reviews, under Czuber.

BrLL, E. G. See Revrews, under Ballantyne.

Birknoff, G. D. An Elementary Double Inequality for the Roots of an Algebraic Equation having Greatest Absolute Value, XXI, 494.

- The Scientific Work of Maxime Bôcher, XXV, 197.

- See REviews, under Angerbach, Blumenthal, Brouwer, Carmichael, Einstein, Lorentz, Poincaré, Weyl, Whitehead, Whittaker.

Blichfeld , H. F. Report on the Theory of the Geometry of Numbers, XXV, 449. - See Reviews, under Blichfeldt.

BuIss, G. A. A Note on the Problem of La grange in the Calculus of Variations, XXII, 220.

- Integrals of Lebesgue, XXIV, 1.

- Solutions of Differential Equations as Functions of the Constants of Integration, XXV, 15 .

- Some Recent Developments in the Calculus of Variations, XXVI, 343.

- A Letter from the President, XXVIII, 16.

- The Reduction of Singularities of Plane Curves by Birational Transformation, XXIX, 161.

- See Reviews, under Blaschke, Osgood, Volterra.

Blumberg, H. A Theorem on Semi-Continuous Functions, XXIV, 381.

- A Theorem on Linear Point Sets, XXV, 350 .

- See Reviews, under Hausdorff.

Bôcher, M. See Birkhoff, G. D., Osgood, W. F., Study, E.

- On a Small Variation which Renders a Linear Differential System Incompatible, XXI, 1.

- The Smallest Characteristic Numbers in a certain Exceptional Case, XXI, 6. See Reviews, under Carse, Gibb.

Borden, R. F. On the Adjoint of a certain Mixed Equation, XXVI, 408.

BoRger, R. L. A Theorem in the Analysis of Real Variables, XXIII, 287.

- On the Cauchy-Goursat Theorem, XXVII, 325, 487.

Bouton, C. L. See OsGood, W. F.

Bray, H. E. Proof of a Formula for an Area, XXIX, 264.

Brouwer, L. E. J. Corrections, XXVI, 135.

Brows, B. H. See Reviews, under Cuny, Neville.

Brown, E. W. George William Hill, 1838-1914, XXI, 499.

- The Relation of Mathematics to the Natural Sciences, XXIII, 213.

- See Reviews, under Annuaire, Bader, Weld, Wilson.

Buck, T. Report of the Twenty-Second Summer Meeting of the American Mathematical Society, XXII, 1.

- Reports of Meetings of the San Francisco Section, XXI, 165; XXII, 172.

Burakss, R. W. See Reviews, under Leib, Yule. 
Carrns, W. D. A Derivation of the Equation of the Normal Probability Curve, XXVI, 105.

Certain Properties of Binomial Coefficients, XXVI, 160.

CaJorI, F. Pierre Laurent Wantzel, XXIV, 339.

- Moritz Cantor, the Historian of Mathematics, XXVIr, 21.

- Augustus De Morgan on Divergent Series, XXVII, 77.

- The Spread of Newtonian and Leibnizian Notations of the Cálculus, XXVII, 453.

- The Name "Divergent" Series, XXIX, 55.

- See Revrews, under Ampère, Andoyer, Carnot, Clairaut, Iamblichus, Laplace, Lavoisier, Monge.

CAMP, B. H. A New Generalization of Tchebycheff's Statistical Inequality, XXVIII, 427.

Cantor, M. See Cajori, F.

Carman, M. G. A Convergence Proof for Simple and Multiple Fourier Series, $\mathrm{XXX}, 410$.

Carmichaet, R. D. Correction, XXI, 206.

- On the Representation of Numbers in the Form $x^{3}+y^{3}+z^{3}-3 x y z$, XXII, 111.

- Examples of a Remarkable Class of Series, XXIII, 407.

- Elementary Inequalities for the Roots of an Algebraic Equation, XXIV, 286.

- General Aspects of the Theory of Summable Series, XXV, 97.

- Note on Convergence Tests for Series and on Stieltjes Integration by Parts, XXVI, 97.

- Note on a Physical Interpretation of Stieltjes Integrals, XXVI, 102, 136.

- Note on Euler's $\varphi$-Function, XXVIII, 109.

- Algebraic Guides to Transcendental Problems, XXVIII, 179.

- See Revrews, under Ahrens, Bateman, Borel, Bowley, Cantor, Castelnuovo, Czuber, Dickson, Duhem, Fabry, Forsyth, Giraud, Goursat, Halphen, Hancock, Hardy, Huntington, Ingersoll, Kramers, Lie, Macaulay, MacRobert, Mendizabal Tamborrel, Mitzscherling, de Montessus, Parker, Pasch, Picard, Riesz, Rutherford, Smith, C. M., Stieltjes, Stolz, de la Vallée Poussin, Voss, Watson, Whitehead.

Carmichael, R. D., and Mason, T. E. Note on the Roots of Algebraic Equations, XXI, 14.

Carslaw, H. S. The Differentiation of a Function of a Function, XXIX, 344.

- See Reviews, under Carslaw.

Carver, W. B. See Reviews, under Phillips.

Carver, W. B., and King, E. F. A Property of Permutation Groups Analogous to Multiple Transivity, XXVI, 319.

ChAo, Y. R. A Note on "Continuous Mathematical Induction," XXVI, 17.

Chase, G. H. See Osgood, W. F.

Chitcenden, E. W. The Converse of the Heine-Borel Theorem in a Riesz

Domain, XXI, 179.
On the Heine-Borel Property in the Theory of Abstract Sets, XXV, 60.

- Note on a Generalization of a Theorem of Baire, XXVII, 5.

- Note on the Division of a Plane by a Point Set, XXVIII, 310.

- Nuclear and Hyper-Nuclear Points in the Theory of Abstract Sets, XXX, 511.

- See Reviews, under Borel.

Coble, A. B. A Covariant of Three Circles, XXVII, 434.

- Cremona Transformations and Applications to Algebra, Geometry, and Modular Functions, XXVIII, 329.

- The Equation of the Eighth Degree, XXX, 301.

- See Reviews, under Malet.

CoLe, F. N. Reports of Meetings of the American Mathematical Society, XXI, 57, 161, 269, 373, 481; XXII, 161, 263, 373, 481; XXIII, 57, 157, 163, 257, 299, 435; XXIV, 57, 169, 265, 369, 465; XXV, 49, 145, 329, 433; XXVI, 145, 241, 337, 433; XXVII, 97.

- Note on Solvable Quintics, XXI, 462.

- Kirkman Parades, XXVIII, 435. 
Cole, F. N. On Simple Groups of Low Order, XXX, 489.

Coolidge. J. L. See Osgood, W. F.

- The Dispersion of Observations, XXVII, 439.

- On the Existence of Curves with Assigned Singularities, XXVIII, 451.

- See Revrews, under Beck, Carslaw, Lehmer, Manning, Sommerville.

Court, N. A. On a Pencil of Nodal Cubics, XXVI, 203.

On a Pencil of Nodal Cubics. Second Paper, XXVII, 114.

Cowley, E. B. See Reviews, under Brenke, Heffter, Kenison, Liebmann, Loria, MacLeod, Merrill, Müller, Pérez, Phillips, Schröder, Skinner.

CraIG, C. F. On the Riemann Zeta Function, XXIX, 337.

- See Reviews, under McClenon, Maurus.

Crathorne, A. R. See Reviews, under Charlier, Fisher, Hancock, Lipka, Loewy, Running.

Cummings, L. D. An Undervalued Kirkman Paper, XXIV, 336.

The Trains for the 36 Groupless Triad Systems on 15 Elements, XXV, 321.

Cummings, L. D., and White, H. S. Groupless Triad Systems on Fifteen Elements, XXII, 12 .

Currier, C. H. See Reviews, under Clements, Holt, Skinner, White.

Curtis, M. F. On the Rectifiability of a Twisted Cubic, XXV, 87.

On the Rectifiability of a Twisted Cubic, XXVI, 275.

- On Skew Parabolas, XXVII, 437.

Curtiss, D. R. Relations between Kindred Riemannian $P$ and $Q$ Functions, XXIX, 154 .

Danield, P. J. The Modular Difference of Classes, XXIII, 446.

- Integrals around General Boundaries, XXV, 65.

- A General Form of Green's Theorem, XXV, 353.

- The Derivative of a Functional, XXV, 414 .

- Stieltjes Derivatives, XXVI, 444.

- See Reviews, under Grammel, Kennelly, Milankovitch, Page.

Darboux, G. See Ersenhart, I. P.

Davis, E. W. See Hedrick, E. R.

- See Reviews, under Davis.

Davis, H. T. Relating to the Proof of an Existence Theorem for a Certain Type of Boundary Value Problem, XXVIII, 390.

- See Reviews, under Cartan.

Drckson, L. E. Invariants, Seminvariants, and Covariants of the Ternary and Quaternary Quadratic Form Modulo 2, XXI, 174.

- On the Relation between Linear Algebras and Continuous Groups, XXII, 53.

- An Extension of the Theory of Numbers by Means of Correspondences between Fields, XXIII, 109.

- Mathematics in War Perspective, XXV, 289.

- Applications of the Geometry of Numbers to Algebraic Numbers, XXV, 453.

- Fallacies and Misconceptions in Diophantine Analysis, XXVII, 312.

- A New Method in Diophantine Analysis, XXVII, 353, 487.

- Impossibility of Restoring Unique Factorization in a Hypercomplex Arithmethic, XXVIII, 438.

- Integral Solutions of $x^{2}-m y^{2}=z w$, XXIX, 464 .

- Algebras and their Arithmetics, XXX, 247.

- Quadratic Fields in which Factorization is Always Unique, XXX, 328.

- See Reviews, unter Bachmann, Carmichael, Lehmer, Leman, Minkowski.

Dines, L. L. Complete Existential Theory of Sheffer's Postulates for Boolean Algebras, XXI, 183.

- Concerning a Suggested and Discarded Generalization of the Weierstrass Factorization Theorem, XXX, 233.

DinI, U. See Ford, W. B.

Douglas, J. Determination of All Systems of $\infty^{4}$ Curves in Space in Which the Sum of the Angles of Every Triangle is Two Right Angles, XXIX, 356.

Dowling, L. W. See Reviews, under Adams, 0. S., Amodeo, Bally, Browne, Deetz, Fazzari, Fricke, Marcolongo, Scritti Matematici. 
Dresden, A. Reports of Meetings of the American Mathematical Society, XXII, 425; XXIII, 251, 387; XXIV, 275, 420; XXVI, 260, 385; XXVII, 49, 293, 401; XXVIII, 148, 285; XXIX, 117, 197; XXX, 217, 389.

A Report on the Scientific Work of the Chicago Section, 1897-1922, XXVIII, 303.

Eliakim Hastings Moore Fund, XXVIII, 307.

Brouwer's Contributions to the Foundations of Mathematics, XXX, 31.

- See Reviews, under Barrow, de Galembert, Goursat, Knopp, Pascal, Richardson, R. P., Riebesell, Shaw, Vivanti.

EisenhaRT, L. P. Darboux's Contribution to Geometry, XXIV, 227.

- The Einstein Solar Field, XXVII, 432.

- Condition that a Tensor be the Curl of a Vector, XXVIII, 425.

- See Reviews, under Bianchi, Darboux, Eddington, Einstein, Schell, Silberstein.

Elston, J. S. See Reviews, under Henry, Spurgeon.

Eмch, A. Note on "The Discovery of Inversion," XXI, 206.

- A certain Class of Functions Connected with Fuchsian Groups, XXII, 33.

- A Theorem on the Curves Described by a Spherical Pendulum, XXIII, 230.

- On the Invariant Net of Cubics in the Steinerian Transformation, XXIV, 327.

- On Plane Algebraic Curves with a Given System of Foci, XXV, 157.

- On a certain Generation of Rational Circular and Isotropic Curves, XXV, 397.

- Kinematics in a Complex Plane and some Geometric Applications, XXVIII, 251.

- Some Problems of Closure Connected with the Geiser 'Transformation, $\mathrm{XXX}, 527$.

- See Reviews, under Bally, Emanaud, Enriques, Field, Ford, L. R., Ganguli, Groll, Jordan, Ling, de Montessus, Saccheri, Scheffers, Study, Winger.

Epperson, C. A. Note on Green's Theorem, XXII, 17.

EtrLINGER, H. J. Extension of an Existence Theorem for a Non-Self-Adjoint Linear System, XXVII, 322.

An Elementary Proof of a Fundamental Lemma Concerning the Limit of a Sum, XXIX, 219.

See Reviews, under Bieberbach, Burkhardt.

Evans, G. C. Note on the Derivative and the Variation of a Function Depending on All the Values of Another Function, XXI, 387.

Application of an Equation in Variable Differences to Integral Equations, XXII, 493.

Corrections and Note to the Cambridge Colloquium of September, 1916, $\mathrm{XXV}, 461$.

Freld, P. A Problem in the Kinematics of a Rigid Body, XXII, 122.

- See Reviews, under Bouny, Burali-Forti, Burgatti, Grammel, Love.

Fischer, C. A. The Legendre Condition for a Minimum of a Double Integral with an Isoperimetric Condition, XXI, 380.

- Note on the Order of Continuity of Functions of Lines, XXIII, 88.

- Necessary and Sufficient Conditions that a Linear Transformation Be Completely Continuous, XXVII, 10, 487.

- See Reviews, under Lévy.

Fiske, T. S. Emory McClintock, XXIII, 353.

Fite, W. B. See Reviews, unter Davis.

ForD, W. B. A Conspectus of the Modern Theory of Divergent Series, XXV, 1.

- A Brief Account of the Life and Work of the Late Professor Ulisse Dini, XXVI, 173.

- On Kakeya's Minimum Area Problem, XXVIII, 45.

Fonsyth, C. H. Tangential Interpolation of Ordinates among Areas, XXIV, 431.

- Formulas for Constructing Abridged Mortality Tables for Decennial Ages, XXVI, 34, 135.

- On the Generalization of certain Fundamental Formulas of the Mathematical Theory of Finance, XXVII, 446.

- See Reviews, under Andoyer, Glover, Soper, Sutton.

ForT, T. Some Theorems of Comparison and Oscillation, XXIV, 330; XXV, 38. 
Foster, M. Surfaces with Orthogonal Loci of the Centers of Geodesic Curvature of an Orthogonal System, XXX, 322.

- Note on a Special Congruence, XXX, 496.

Frankuin, P. Two Theorems on Multiple Integrals, XXVIII, 433.

- A Qualitative Definition of the Trigonometric and Hyperbolic Functions, XXIX, 56.

A Qualitative Definition of the Potential Functions, XXX, 41.

Fréchet, M. On Pierpont's Definition of Integrals, XXII, 295.

- On Pierpont's Integral. Reply to Professor Pierpont, XXIII, 172.

Frizeld, A. B. An Enumeration of Integral Algebraic Polynomials, XXI, 341.

- Certain Non-Enumerable Sets of Infinite Permutations, XXI, 495.

- The Permutations of the Natural Numbers Can Not Be Well Ordered, XXII, 71.

GABA, M. G. A Set of Completely Independent Postulates for the Linear Order $\eta$, XXVI, 158.

- A Set of Axioms for Line Geometry, XXIX, 128.

- See Reviews, under Young, J. W.

Gillespie, D. C. A Property of Continuity, XXVIII, 245.

GrnsburG, J. New Light on our Numerals, with introductory note by D. E. SмIтH, XXIII, 366, 467 .

Glens, 0. E. Modular Invariant Processes, XXI, 167.

- Translation Surfaces Associated with Line Congruences, XXIII, 122.

- The Invariants of Forms under the Binary Linear Homogeneous Group $G_{6}$ Modulo 2, XXX, 131.

- See Reviews, under Dickson, Engelhardt, Netto.

Glover, J. W. See Reviews, under Richard.

Graustein, W. C. Note on Isogenous Complex Functions of Curves, XXIV, 473.

- Note on a certain Type of Ruled Surface, XXIX, 341.

- Applicability with Preservation of Both Curvatures, XXX, 19.

- The Scientific Work of Joseph Lipka, XXX, 352.

- See Reviews, under Bouligand, Dickson, Eisenhart, de Tannenberg.

Graves, G. H. See Reviews, under Thompson, A. W. H.

Green, G. M. See Wilczynski, E. J.

- On the Linear Dependence of Functions of one Variable, XXIII, 118.

- Note on Conjugate Nets with Equal Point Invariants, XXIV, 221.

Griffin, F. L. See Reviews, under Martin.

GronwalL, T. H. On Approximation by Trigonometric Sums, XXI, 9.

- A Sequence of Polynomials Connected with the $n$th Roots of Unity, XXVII, 275.

- On the Fourier Coefficients of a Continuous Function, XXVII, 320.

- See Reviews, under Borel, Cahen, Darboux, Gans, Klein, Liebmann, Mathematische Abhandlungen, Näbauer, Netto, Neumann, Rothe, R., Runge.

Grove, C. C. See Reviews, under Bartlett, Horsburgh, Mann, Wentworth, Zaldari.

Hallett, G. H. Concerning the Definition of a Simple Continuous Arc, XXV, 325.

Hancock, H. Remarks on Elliptic Integrals, XXIV, 487.

- On the Evaluation of the Elliptic Transcendents $\eta_{2}$ and $\eta_{2}^{\prime}, \mathrm{XXV}, 150$.

Hart, W. L. Note on Infinite Systems of Linear Equations, XXIV, 334.

- The Pseudo-Derivative of a Summable Function, XXVII, 202.

- Summable Infinite Determinants, XXVIII, 171,

Haskels, M. W. The Maximum Number of Cusps of an Algebraic Plane Curve, and Enumeration of Self-Dual Curves, XXIII, 164.

- See Reviews, under von Mangoldt.

Haskins, C. N. Mr. Paaswell's Appeal to Producing Mathematicians, XXI, 343.

Hayashi, T. On the Problem of the Resistance Integral, XXV, 131.

A Theorem on Areas, XXV, 324.

- On the Rectifiability of a Twisted Cubic, XXVI, 73, 136.

Hazlete, 0. C. See Reviews, under Dickson, Scorza.

HeDrICK, E. R. In Memoriam: Ellery William Davis, XXV, 36.

- See Reviews, under Hadamard. 
Hildebrandt, T. H. On a Generalization of a Theorem of Dini on Sequences of Continuous Functions, XXI, 113.

- On Integrals Related to and Extensions of the Lebesgue Integrals, XXIV, $113,177$.

- On Bordered Fredholm Determinants, XXVI, 400.

- Convergence of Sequences of Linear Operations, XXVIII, 53.

- On Uniform Limitedness of Sets of Functional Operations, XXIX, 309.

- See Revrews, under Knopp.

Hill, G. W. See Brown, E. W.

Hille, E. Convex Distribution of the Zeros of Sturm-Liouville Functions, XXVIII, 261, 462.

Hilton, H. A Generalization of a Property of an Acnodal Cubic Curve, XXIX, $303,417$.

- On a Type of Plane Unicursal Curve, XXX, 317.

Hitchcock, F. L. See Reviews, under Hall, Naess.

HollcrofT, T. R. Singularities of Curves of Given Order, XXIX, 407.

Hoskins, L. M. Report of the Forty-Second Regular Meeting of the San Francisco Section, XXX, 12.

Huntington, E. V. Complete Existential Theory of the Postulates for Serial Order, XXIII, 276.

- Complete Existential Theory of the Postulates forWell Ordered Sets, XXIII,280.

Hurwitz, W. A. The Chicago Colloquium, XXVII, 65.

- Report on Topics in the Theory of Divergent Series, XXVIII, 17.

- See Reviews, under Hardy.

INGoLD, L. Report of the Thirteenth Regular Meeting of the Southwestern Section, XXVII, 197.

- See Reviews, under Bieberbach.

JACKson, D. An Elementary Boundary Value Problem, XXII, 393.

- Note on the Parametric Representation of an Arbitrary Continuous Curve, XXIV, 77.

- Note on a Method of Proof in the Theory of Fourier's Series, XXVII, 108.

- Note on the Median of a Set of Numbers, XXVII, 160.

- The General Theory of Approximation by Polynomials and Trigonometric Sums, XXVII, 415.

- Note on an Irregular Expansion Problem, XXVIII, 37.

- Note on Quartiles and Allied Measures, XXIX, 17.

- Note on the Convergence of Weighted Trigonometric Series, XXIX, 259.

- A Symmetric Coefficient of Correlation for Several Variables, XXX, 536.

- See Reviews, under Hahn, de la Vallée Poussin.

Karpinski, L. C. See Reviews, under Archibald, De Morgan, Fazzari, Gunther, Lange, Slichter, Wieleitner.

KAsner, E. Equilong Invariants and Convergence Proofs, XXIII, 341.

KelloGG, D. D. Reports of Meetings of the Southwestern Section, XXI, 217; XXII, 215; XXIII, 208; XXIV, 217; XXVI, 260.

- Note on Closure of Orthogonal Sets, XXVII, 165.

- A Property of Certain Functions Whose Sturmian Developments Do Not Terminate, XXVIII, 388.

- See Reviews, under Hurwitz, Rothe, H.

KempNer, A. J. See Reviews, under Bachmann, Perron.

Kenyon, A. M. See Reviews, under Bell.

Keyser, C. J. The Rôle of the Concept of Infinity in the Work of Lucretius, XXIV, 321 .

- Note Concerning the Number of Possible Interpretations of any System of Postulates, XXIV, 391.

- See Reviews, under Berkeley, Russell, Wittgenstein.

King, E. F. See Carver, W. B. 
KuINE, J. R. Concerning the Complement of a Countable Infinity of Point Sets of a certain Type, XXIII, 290.

Koopman, B. 0. See Reviews, under Madelung.

Küstermann, W. W. Proof of the Convergence of Poisson's Integral for NonAbsolutely Integrable Functions, XX, 120.

Kulischer, A. R. See Vecchi, M.

Lamson, K. W. See Reviews, under Eddington.

LANE, E. P. A Characterization of Surfaces of Translation, XXX, 231.

- See Reviews, under Cartan.

Laves, K. See Reviews, under Andoyer.

Lefschetz, S. The Equation of Picard-Fuchs for an Algebraic Surface with Arbitrary Singularities, XXI, 227.

- Report on Curves Traced on Algebraic Surfaces, XXIX, 242.

- See Reviews, under Severi, Veblen.

Lehmer, D. N. See Reviews, under Cunningham, Dickson, Inghirami, Lebon, Poletti.

LeIB, D. D. See Reviews, under Elliott, Killing.

LigHT, G. H. The Intrinsic Equation for Euler's Resistance Integral, XXIV, 480.

LiNfield, B. Z. On the Relation of the Roots and Poles of a Rational Function to the Roots of its Derivative, XXVII, 17.

Lipka, J. See Graustein, W. C.

- Note on Velocity Systems in Curved Space of $N$ Dimensions, XXVII, 71.

- On the Relative Curvature of Two Curves in $V_{n}, \mathrm{XXIX}, 345$.

- See Reviews, under Ensslin, Longley.

Longley, W. R. See Reviews, under Guichard, Herglotz, Lecornu, Nernst, Prescott.

Loria, G. The Physicist J. B. Porta as a Geometer, translated by M. A. Batta, XXII, 340 .

A Remark on Skew Parabolas, XXVII, 201.

Lovitr, W. V. A Type of Singular Points for a Transformation of Three Variables, XXII, 236.

- Singular Points of Transformations and Two-Parameter Families of Curves, XXII, 387.

See Reviews, under MacMahon, March, Popplewell, Secrist.

Luns, A. C. Some Functional Equations in the Theory of Relativity, XXVI, 26.

Lytre, E. B. See Reviews, under Branford, Cobb, Collins, Syllabus of Mathematics, Whiteford.

McAtee, J. E. The Transformation of a Regular Group into its Conjoint, $\mathrm{XXV}, 326$.

McClenon, R. B. See Reviews, under Archimedes, de Fermat, Heath, Tropfke, Tweedie.

McClintock, E. See Fiske, T. S.

McDonaLd, J. H. The Transformation of Elliptic Integrals, XXVII, 366.

McKelvey, J. V. See Reviews, under von Dalwigk, Smith, D. E.

MacDuffee, C. C. On Transformable Systems and Covariants of Algebraic Forms, XXIX, 26.

MacMillan, W. D. Convergence of the Series $\sum_{i=0}^{\infty} \sum_{j=0}^{\infty}\left(x^{i} y^{j} /(i-j \gamma)\right)$ ( $\gamma$ Irrational), XXII, 26.

The Moment of Inertia in the Problem of $n$ Bodies, XXVIII, 165.

See REviews, under Goursat, Schlesinger.

MacNeish, H. F. The Sum of the Face Angles of certain Polyhedrons in $n$-Space, XXVI, 398.

Manning, W. A. Reports of Meetings of the San Francisco Section, XXIII, 203, 401; XXIV, 175.

- See Reviews, under Pierpont.

Mason, T. E. See CarmichaEL, R. D.

- See Reviews, under Caunt, Hudson, R. G., Ichak, M'Lachlan, Macfarlane.

Mathewson, L. C. See Reviews, under Baumgartner, Kraïtchik, Poirée. 
Michal, A. D. Integro-Differential Invariants of One-Parameter Groups of Fredholm Transformations, XXX, 338.

Miller, A. L. An Analogue to Pascal's Theorem, XXIII, 292.

Mrlleer, G. A. Note on the Potential and the Anti-Potential Group of a Given Group, XXI, 221.

Limits of the Degree of Transitivity of Substitution Groups, XXII, 68.

Graphical Method of Finding the Possible Sets of Independent Generators of an Abelian Group, XXIII, 14.

Groups Generated by Two Operators of the same Prime Order Such That the Conjugates of One under the Powers of the Other Are Commutative, XXIII, 283.

Groups Formed by Special Matrices, XXIV, 203.

Determinant Groups, XXV, 69.

Groups Containing a Relatively Large Number of Operators of Order Two, $\mathrm{XXV}, 408$.

Form of the Number of Subgroups of Prime Power Groups, XXVI, 66.

Groups Generated by Two Operators of Order Three Whose Product Is of Order Four, XXVI, 361.

- Reciprocal Subgroups of an Abelian Group, XXVII, 266.

- Group Theory Reviews in the Jahrbuch über die Fortschritte der Mathematik, XXVII, 459.

The Simple Group of Order 2520, XXVIII, 98.

- Substitutions Commutative with Every Substitution of an Intransitive Group, XXVIII, 168.

Groups in Which the Number of Operators in a Set of Conjugates is Equal to the Order of the Commutator Subgroup, XXIX, 64.

Same Left Co-Set and Right Co-Set Multipliers for any Given Finite Group, XXIX, 394.

- Number of Cycles of the Same Order in any Given Substitution Group, XXX, 239.

- See Reviews, under Cajori, Speiser.

Milne, W. E. Note on Removable Singularities, XXI, 116.

- Second Note on Removable Singularities, XXIII, 27.

- Note on Asymptotic Expressions in the Theory of Linear Differential Equations, XXIII, 166.

Infinite Systems of Functions, XXVI, 294.

A Theorem of Oscillation, XXVIII, 102.

Mitcheld, H. H. See Reviews, under Blichfeldt, Fraenkel.

Mittag-Leffler, G. The Mittag-Leffler Testament and Institute, translated by C. E. SEELY, XXIII, 31.

Moore, C. L. E. Translation Surfaces in Hyperspace, XXV, 75.

- Rotation Surfaces of Constant Curvature in Space of Four Dimensions, XXVI, 454.

- Note on Minimal Varieties in Hyperspace, XXVII, 211.

- See Reviews, under Lotze, d'Ocagne, Planck, Struik, Williams, K. P.

Moore, C. N. On the Developments in Bessel's Functions, XXIII, 18.

A Continuous Function Whose Development in Bessel's Functions is NonSummable of Certain Orders, XXIV, 145.

- Applications of the Theory of Summability to Developments in Orthogonal Functions, XXV, 258.

- See Reviews, under Carslaw, Eddington, Ford, W. B., Forsyth, Goursat, Hadamard, Hobson, Karpinski, Picard, Pringsheim, A., Wangerin.

Moore, R. L. On the Linear Continuum, XXII, 117.

Concerning a Non-Metrical Pseudo-Archimedean Axiom, XXII, 225.

- A Theorem Concerning Continuous Curves, XXIII, 233.

- Continuous Sets that Have no Continuous Sets of Condensation, XXV, 174.

- An Uncountable, Closed, and Non-Dense Point Set Each of Whose Complementary Intervals Abuts on Another One at Each of its Ends, XXIX, 49.

- Report on Continuous Curves from the Viewpoint of Analysis Situs, XXIX, 289.

- Concerning Relatively Uniform Convergence, XXX, 504.

- See Reviews, under Veblen. 
MoRdell, L. J. An Introductory Account of the Arithmetical Theory of Algebraic Numbers and its Recent Developments, XXIX, 445.

Morgan, F. M. See Reviews, under Aubert, Beutel, Carey, Hilton, Long, Marsh, H. W., Salmon, Wilczynski, Williams, J. H., Woods.

Moritz, R. E. Concerning Reviews, XXII, 398.

MorLeY, F. Pleasant Questions and Wonderful Effects, XXVII, 309.

Monse, H. M. Proof of a General Theorem on the Linear Dependence of $p$ Analytic Functions of a Single Variable, XXIII, 114.

Moulton, E. J. Reports of Meetings of the American Mathematical Society, XXV, 241, 329, 385; XXVI, 49.

Murnaghan, F. D. See Reviews, under Bridgman.

MurRaY, F. H. On Implicit Functions, XXVII, 111.

- Periodic Solutions in the Problem of Three Bodies, XXIX, 15.

- Note on Stability à la Poisson, XXX, 17.

Nelson, A. L. Quasi-Periodicity of Asymptotic Plane Nets, XXII, 445.

NobLe, C. A. Report of the Forty-Third Regular Meeting of the San Francisco Section, XXX, 385 .

OsGood, W. F. Note on Functions of Several Complex Variables, XXII, 443.

- Singular Points of Analytic Transformations, XXIII, 404.

- On a Theorem of Oscillation, XXV, 216.

- The Life and Services of Maxime Bôcher, XXV, 337.

Osgood, W. F., Coolidge, J. L., and Chase, G.H. Charles Leonard Bouton, XXVIII, 123.

Owens, F. W. See Reviews, under Dowling, Woods, Zühlke.

PaAswell, G. An Appeal to Producing Mathematicians, XXI, 127.

Pfeiffer, G. A. Note on the Linear Dependence of Analytic Functions, XXIII, 117.

- A Correction, XXX, 270.

- See Reviews, under Fraenkel, Russell.

Phillips, H. B. See Reviews, under Gray, Kaye, Möller, Reiche, Shaw, Townsend.

Pierpont, J. M. Reply to Professor Fréchet's Article, XXII, 298.

- A Reply to a Reply, XXIII, 174.

- See Reviews, under Hermite.

Pitcher, A. D. On the Coherence of certain Systems in General Analysis, XXVI, 405.

- In Memoriam, XXX, 155.

- See Reviews, under Encyklopädie, Young, J. W.

Ponzer, E. W. See Reviews, under Bayliss, Demartres, Durell, Fabry, Furtwängler, Lenz, Ott.

Poor, V. C. Transformation Theorems in the Theory of the Linear Vector Function, XXII, 174.

- Operators in Vector Analysis, XXII, 503.

Poritskx, H. On Curves Kinematically Related to a Given Curve, XXIX, 71.

Porter, M. B. Concerning Absolutely Continuous Functions, XXII, 109.

- Derivativeless Continuous Funetions, XXV, 176.

- A Two-Way Infinite Series for Lebesgue Integrals, XXVIII, 105.

- The Second Mean Value Theorem for Summable Functions, XXIX, 399.

- See Reviews, under de la Vallée Poussin.

Putnam, T. M. See Reviews, under Whitford.

Ranum, A. See Reviews, under Miller, G. A.

REYNoLDs, C. N. Note on Linear Differential Equations of the Fourth Order whose Solutions Satisfy a Homogeneous Quadratic Identity, XXVI, 277.

- See Reviews, under Becquerel, Cassirer, Fabre, Fournier, Kohler, Kopff, Mie, Rice.

Richardson, R. G. D. Reports of Meetings of the American Mathematical Society, XXVII, 245, 341, 389; XXVIII, 1, 89, 148, 233, 285, 377; XXIX, 1, 97, 145, 204, 433; XXX, 4, 199, 291, 481 . 
RIChardson, R. G. D. The Frank Nelson Cole Prize in Algebra, XXIX, 14.

- Incorporation of the American Mathematical Society, XXIX, 241.

- The Josiah Willard Gibbs Lectureship, XXIX, 385.

- On the Reality of the Zeros of a $\lambda$-Determinant, XXIX, 467.

- Incorporation of the American Mathematical Society, XXX, 1.

- The Bôcher Memorial Prize, XXX, 193.

- The First Josiah Willard Gibbs Lecture, XXX, 289.

- See Reviews, under Betz, Bôcher.

Richmond, H. W. The Equation of a Plane Rational Curve Defined by Parametric Equations, XXIII 90.

Rider, P. R. A Note on Discontinuous Solutions in the Calculus of Variations, XXIII, 237.

A Theorem on the Variation of a Function, XXIV, 430.

- The Minimum Area between a Curve and its Caustic, XXVII, 279.

Rierz, H. L. On certain Topics in the Mathematical Theory of Statistics, $\mathrm{XXX}, 417$.

- See Reviews, under Czuber, Glover, Huygens, Insolera, Kelley.

RITT, J. F. On the Differentiability of Asymptotic Series, XXIV, 225.

- Note on Equal Continuity, XXVII, 351.

- Analytic Functions and Periodicity, XXX, 406.

- See Reviews, under Petrovitch.

Robisns, R. B. See Reviews, under Crantz, Richardson, S. F.

RoEver, W. H. A Geometric Derivation of a General Formula for the Southerly Deviation of Freely Falling Bodies, XXI, 444.

Rowe, J. E. Relations among Parameters along the Rational Cubic Curve, XXII, 74.

- A New Method of Finding the Equation of a Rational Plane Curve from its Parametric Equations, XXII, 338.

- The Equation of a Rational Plane Curve Derived from its Parametric Equations (second paper), XXIII, 304.

- The Projection of a Line Section upon the Rational Plane Cubic Curve, XXIII, 405.

Related Invariants of Two Rational Sextics, XXV, 34.

- See Reviews, under Dufrenois, Fite, Ordnance Department, Vahlen.

SAFFord, F. H. Irrational Transformations of the General Elliptic Element, XXIV, 74 .

- Surfaces of Revolution in the Theory of Lamés Products, XXIV, 384.

- Reduction of the Elliptic Element to the Weierstrass Form, XXVI, 13.

- Parametric Equations of the Path of a Projectile when the Air Resistance Varies as the $n$th Power of the Velocity, XXVI, 289; XXVII, 487.

- See Reviews, under Bôcher, Lepper, Marsh, H. W., Minchin, Wentworth.

SchweItzer, A. R. Remarks on Functional Equations, XXI, 23.

Seely, C. E. See MittaG-Leffler, G.

ShAw, J. B. See Reviews, under Appell, Bhattacharyya, Boussinesq, Boutroux, Conway, Cullis, Dumont, Gans, Isenkrahe, Juvet, Keyser, Lacaze, Leveugle, Perry, Poincaré, Robb, Runge, Silberstein, Valentiner, Volterra, Weatherburn, Weber, R. H., Zoretti.

Shoнat, J. A. The Theory of Closure of Tchebycheff Polynomials for an Infinite Interval, XXX, 505.

Silverman, L. L. Note on Regular Transformations, XXII, 459.

- See Reviews, under Bolzano.

Sisam, C. H. On a Configuration on certain Surfaces, XXII, 381.

- See Revirws, under Berzolari, Pascal.

Skinner, E. B. See Reviews, under Châtelet, Hilton.

Sladart, H. E. Reports of Meetings of the American Mathematical Society, XXI, 285, 429; XXII, 280.

Slocum, S. E. See Reviews, under Breslich, Evans, G. W., Finney, Flamard, Martin, Taylor, Wentworth.

Smith, D. E. See Ginsbura, J.

- The Napier Tercentenary Celebration, XXI, 123. 
SмIтн, D. E. John Wallis as a Cryptographer, XXIV, 82.

- The Mathematical Congress at Strasbourg, XXVII, 104.

- See Reviews, under Ahrens, Archibald, Archimedes, Ball, Barnard, Bibliotheca Bioche, Breslich, Bryant, Cajori, Child, Eymieu, Gifford, Heath, Hill Karpinski, Kirchberger, Knott, Lefebvre, Loria, Nunn, Peet, Reeve, Torri. celli, Van Tuyl, Zeuthen.

Smith, E. R. See Reviews, under Smith, P. F.

Smith, P. F. See Reviews, under Hort.

SNyder, V. The Cambridge Colloquium, XXIII, 81, 164.

- Mathematics at an Italian Technical School, XXIII, 149.

- Problems in Involutorial Transformations of Space, XXX, 101.

- See Reviews, under Armstrong, Auerbach, Doehlemann, Grossmann, Hatton, Hedrick, Hjelmslev, Hudson, H. P., Ince, Klein, Meyer, Miller, H. W., Müller, Salmon, von Sanden, Schmid.

Sommerville, D.M.Y. Quadratic Systems of Circles in Non-Euclidean Geometry, $\mathrm{XXV}, 161$.

Southall, J. P. C. See Reviews, under Huygens.

Stoufrer, E. B. Reports of Meetings of the Southwestern Section, XXVIII, $145 ; \mathrm{XXIX}, 125 ; \mathrm{XXX}, 97$.

- See Reviews, under Kommerell, V.

Study, E., and BôcHer, M. Professor Bôcher's Views concerning the Geometry of Inversion, XXII, 38.

Swift, E. See Reviews, under Runge.

TAYLOR, J. S. Sheffer's Set of Five Postulates for Boolean Algebras in Terms of the Operation 'Rejection' Made Completely Independent, XXVI, 449.

VAN Der VRIES, J. N. See Reviews, under Schuh.

VANDIVER, H. S. An Aspect of the Linear Congruence with Applications to the Theory of Fermat's Quotient, XXII, 61.

- Note on the Distribution of Quadratic Residues, XXIII, 111.

- Proof of a Property of the Norm of a Cyclotomic Integer, XXV, 221.

- On the First Factor of the Class Number of a Cyclotomic Field, XXV, 458.

- Note on Some Results Concerning Fermat's Last Theorem, XXVIII, 258.

- On Kummer's Memoir of 1857 Concerning Fermat's Last Theorem, XXVIII, 400.

- Methods for Finding Factors of Large Integers, XXX, 542.

- See Reviews, under Bachmann, Dickson.

VAN VLECK, E. B. The Rôle of the Point-Set Theory in Geometry and Dynamics,

XXI, 321.
Current Tendencies of Mathematical Research, XXIII, 1.

The Bôcher Memorial Prize, XXVIII, 42.

Veblen, O. Invariance of the Poincaré Numbers of a Discrete Group, XXX, 405. - See Reviews, under Birkhoff.

VECCHI, M. On the Characteristics of the Principal Manuals of Elementary Geometry Published in Italy in the Course of the Last Fifty Years, translated by A. R. KULISCHER, XXI, 188.

Wahlin, G. E. On the Principal Units of an Algebraic Domain $k(\mathfrak{p}, \alpha)$ XXIII, 450.

- On the Application of the Theory of Ideals to Diophantine Analysis, XXX, 140.

- See Reviews, under Bianchi, Fraenkel, Hecke, Landau, Mordell.

WaLsh, J. L. On the Proof of Cauchy's Integral Formula by Means of Green's Formula, XXVI, 155.

- A Generalization of Normal Congruences of Circles, XXVIII, 456.

- On the Location of the Roots of Polynomials, XXX, 51.

- See Reviews, under Congrès.

Wantzel, P. L. See CaJori, F.

Wear, L. E. The Self-Dual Plane Rational Quintic, XXV, 405.

Weaver, J. H. Pappus. Introductory Paper, XXIII, 127.

- On Foci of Conics, XXIII, 357.

- Some Algebraic Curves, XXV, 85, 329. 
WeIsner, L. Group of a Set of Simultaneous Algebraic Equations, XXX, 314. Wells, M. E. See Reviews, under Barker.

White, H. S. See Cummings, L. D.

- See Reviews, under Coolidge, Cremona.

WhittemoRe, J. K. Trajectories and Flat Points on Ruled Surfaces, XXV, 223.

- Ruled Surfaces with Director Planes, XXIX, 21.

- Total Geodesic Curvature and Geodesic Torsion, XXIX, 51.

Wiener, N. Certain Iterative Characteristics of Bilinear Operations, XXVII, 6.

- The Isomorphisms of Complex Algebra, XXVII, 443.

- See Reviews, under Carnap, Study, Weyl.

Wilczynski, E. J. Some Remarks on the Historical Development and the Future Prospects of the Differential Geometry of Plane Curves, XXII, 317. In Memory of Gabriel Marcus Green, XXVI, 1.

Wilder, C. E. See Reviews, under Murnaghan.

WiLliaMs, K. P. Concerning a certain Totally Discontinuous Function, XXI, 117.

Concerning Hill's Derivation of the Lagrange Equations of Motion, XXII, 455.

Note Concerning the Roots of an Equation, XXVIII, 394.

See Reviews, under Jacoby.

WILson, E. B. Infinite Regions in Geometry, XXI, 73.

- Changing Surface to Volume Integrals, XXII, 336.

On Notational Equivalence, XXIII, 169.

See Reviews, under Czuber, Davis, Eccles, Eddington, Granville, Grassmann, H., Greenhill, Jeans, Keynes, Lamb, Lorentz, Minkowski, Schaefer, Silberstein, Snyder, Vance, Vivanti, Wood.

Wilson, W. A. On Separated Sets, XXII, 384.

WILson, W. H. On certain Related Functional Equations, XXVI, 300.

Winger, R. M. Report of a Special Meeting of the San Francisco Section, XXX, 194.

- Involutions on the Rational Cubic, XXV, 27.

- Some Generalizations of the Satellite Theory, XXVI, 75.

- See Reviews, under Snyder.

Young, J. W. See Reviews, under Benny, Bisacre, Bolton, Boutroux, Dendy, Granville, Heffter, Heiberg, Keyser, Kowalewski, A., Kowalewski, G., Michel, Neville, Riemann, Smith, D. E., Weber, H.

Young, J. W. A. See Reviews, under Lietzmann.

Zeldin, S. D. Note on Steady Fluid Motion, XXVIII, 313. 